\title{
De la Figura del Defensor del Usuario de la Administración Electrónica
}

\author{
Gustavo Aguilera Izaguirre \\ Doctor en Derecho, Universidad de Salamanca, España. Máster en Estado de Derecho y Corrupción, Universidad de \\ Salamanca, España. Especialidad en Ciencias Politicas y Estudios Constitucionales, el Centro de Estudios Politicos \\ y Constitucionales del Ministerio de la Presidencia de España. Docente Investigador, Facultad de Derecho de la \\ Universidad Autónoma del Estado de México.E-mail:gusyr37@hotmail.com
}

Rosa Amelia Domínguez, Arteaga

Doctora en Ciencias de la Información, Universidad Carlos III de Madrid, España. Máster en Documentación e Investigación en Comunicación por la Universidad Carlos III de Madrid, España. Docente Investigador El Colegio de Tamaulipas, México. E-mail: ameliadguez@gmail.com

\section{Resumen}

El presente trabajo de investigación se centra por un lado en el estudio del desarrollo de la Administración Electrónica, esto es, en la utilización de las TIC que se ha producido en el interior de las Administraciones Públicas, analizando algunos de los planes que en esta materia se han llevado a cabo, así como también en el estudio de la LAECSP, enfocándonos en uno de los medios para garantizar los derechos de los ciudadanos frente a la Administración electrónica, como lo es la figura del Defensor del Usuario. La importancia de la LAECSP en España consiste en destacar en el reconocimiento de nuevos derechos a los ciudadanos en su relación con las Administraciones Públicas, la posibilidad de realizar trámites desde cualquier lugar y momento, y por tanto esto se traduce en contar con una administración más ágil y eficaz; así como la mención de la figura de un Defensor del Usuario de la Administración electrónica.

Palabras clave: Administración electrónica, Nuevas tecnologías, Defensor del usuario de la administración electrónica.

\section{Abstract}

The present research focuses on the one hand in the study of e-government development, that is, in the use of ICT that has occurred within the government, analyzing some of the plans in this area have been carried out, as well as in the study of LAECSP, focusing on one of the means to guarantee the rights of citizens in relation to e-Government, such as the Defender of the user. The importance of LAECSP in Spain is to highlight the recognition of new rights to citiz ens in their relationship with government, the possibility of completing from any place and time, and therefore this results in having an administration more quickly and efficiently, as well as the mention of the figure of a user Ombudsman e-Government.

Keywords: e-Government, New Technology, User Ombudsman eGovernment.

\section{Résumé}

Cette recherche se concentre d'une part sur l'étude du développement de l'administration en ligne, à savoir l'utilisation des TIC qui a eu lieu au sein du gouvernement, d'analyser certains des plans dans ce domaine ont été réalisées, ainsi que dans l'étude de LAECSP, mettant l'accent sur l'un des moyens de garantir les droits des citoyens par rapport à l'administration en ligne, comme le défenseur de l'utilisateur. L'importance de LAECSP en Espagne est de mettre en évidence la reconnaissance de nouveaux droits aux citoyens dans leurs relations avec le gouvernement, la capacité d'effectuer des transactions à partir de n'importe quel endroit et de l'heure, et donc il en résulte ayant une administration plus souple et efficace; ainsi que des références à la figure d'un e-gouvernement de l'avocat de l'utilisateur.

Mots-clés: L'administration en ligne, Les nouvelles technologies, L'avocat de l'utilisateur d'administration en ligne. 



\title{
De la Figura del Defensor del Usuario de la Administración Electrónica
}

\author{
Gustavo Aguilera Izaguirre \\ Rosa Amelia Domínguez Arteaga
}

\section{INTRODUCCIÓN}

La incorporación de las TIC en las Administraciones Públicas de los países europeos como Inglaterra, Francia, Italia y países americanos como Estados Unidos, ha significado un importante desarrollo en su funcionamiento interno, además de la elevación de la calidad de los servicios que éstas prestan a los ciudadanos. España por supuesto, no podía permanecer estática ante tal acontecimiento. Por ello, desde 1990 a la actualidad España ha promovido iniciativas con el fin de establecer una Administración electrónica que logren su desarrollo e impulso que van desde la elaboración de políticas en esta materia, hasta la creación de un marco legal.

En este sentido, algunos de los pasos llevados a cabo, por mencionar algunos, fueron la presentación de planes como Info XXI, plan de choque denominado España, entre otros, pero sin duda dentro del marco legal, uno de los pasos más importantes fue, la LAECSP, el cual, hay que señalar, es una de varias leyes que en materia de administración electrónica se han dado, algunas de orden menor dentro del plan modernizador de las Administraciones públicas españolas.

La importancia de la LAECSP en España es en principio una norma cuyo contenido avanzado solamente tienen otros países como Estados Unidos, Italia, Finlandia, y Austria. Ese contenido avanzado a destacar, consiste en el reconocimiento de nuevos derechos a los ciudadanos en su relación con las Administraciones Públicas, la posibilidad de realizar trámites desde cualquier lugar y momento, y por tanto, esto se traduce en contar con una administración más ágil y eficaz; así como la mención de la figura de un Defensor del Usuario de la Administración Electrónica.

\section{DE LA ADMINISTRACIÓN ELECTRÓNICA}

El concepto de administración electrónica es relativamente nuevo y puede ser objeto de confusión con otros términos equivalentes, como administración digital, gobierno electrónico, administración en línea o ciberadministración, entre otros (Martínez, 2007). Por lo tanto, es importante empezar a distinguir en la medida de lo posible, la diferencia que pueda existir entre las diferentes denominaciones antes mencionadas, con el fin de evitar confusiones y dejar establecido el concepto que tomaremos en cuenta a efectos del desarrollo del presente trabajo de investigación. 
Cuando hablamos de Administración digital, se hace referencia al término inglés digital goverment, y que mayormente se usa en el ámbito anglosajón. Distinto el caso, cuando hablamos del término gobierno electrónico (electronic goverment) y administración electrónica (electronic administration). En el caso del primero, éste ha sido mayormente difundido en la literatura especializada en castellano pero con mayor aplicación en latinoamérica; en tanto que, la denominada Administración electrónica, ha tenido mayor aceptación dentro de la documentacion de la Unión Europea, y por consiguiente, en la documentacion relativa a las políticas de información en España, ambas aglomeran la mayoría de las denominaciones en la literatura especializada en castellano.

En el caso de la Administración en línea (on line) se utiliza más bien, para referirse al conjunto de actividades de gestión informática de ámbito privado que se realizan de forma no presencial. En el caso de gobierno en línea (on line) se refiera básicamente a los programas de Administración electrónica auspiciados por el grupo de los 8 y que se han denominado Goverment On line. En cuanto al término ciberadministración, éste ha sido utilizado como sinónimo de Administración electrónica.

Para algunos autores, todas las anteriores denominaciones son en realidad la traducción en español de e-goverment, por ser el término más difundido internacionalmente. Algo con lo que no estamos de acuerdo, por ser "gobierno" y "administración" conceptos relacionados entre sí, pero distintos en el desarrollo de los temas analizaremos la distinción de estos conceptos.

\subsection{Definición de la Administración Electrónica}

La Modernización administrativa implica que las Administraciones públicas han de ir adaptándose a cada uno de los factores de cambio. Uno de estos factores en la actualidad es la utilización de las tecnologías de la información y comunicación ${ }^{1}$, como una herramienta utilizada cada vez más por la sociedad. La Modernización en sí, lo que trata fundamentalmente es dar respuesta a las demandas de la sociedad incorporando las TIC a su estructura, estableciéndose así una nueva forma de relación entre ambos, mediante el uso de nuevas técnicas de la sociedad de la información ${ }^{2}$.

En un inicio fueron la empresa privada y la sociedad civil los que asumieron la utilización de la TIC, y en donde quedó demostrada la eficacia de la utilización de las innovaciones tecnológicas. En ese momento, la Administración decide incorporar en su forma de actuar los mecanismos necesarios para adaptarse a la sociedad privada.

La importancia de las TIC para las administraciones públicas y para la sociedad en general, se caracteriza por la utilización de nuevas tecnologías para actuar sobre

1 En adelante TIC, que son los servicios, aplicaciones, equipos y programas informativos, es decir, herramientas, como la telefonía, el aprendizaje a distancia, televisión, computadoras, redes e Internet.

2 La sociedad de la información se puede definir como cualquier conglomerado humano cuyas acciones de supervivencia y desarrollo basado predominantemente en un intenso uso, distribución, almacenamiento y creación de recursos de información y comunicación (Ponjuán, 1998) 
la información. Internet es un instrumento para poder acceder a la información en cualquier momento todos los días del año y a todas horas. Por otro lado, otras de las características sería la capacidad de la red para adaptarse a la interacción creciente, así como a las pautas de desarrollo de esta interacción. En definitiva, internet tiene una gran capacidad para la flexibilidad ante los nuevos cambios en las organizaciones e instituciones, en una sociedad que en la actualidad está dominada por los cambios constantes (Castells, 2001).

Las TIC ofrecen a las Administraciones públicas nuevos mecanismos a través de los cuales los ciudadanos (clientes) pueden recibir información y servicios de forma más rápida, cómoda y eficiente. El hecho de considerar a los ciudadanos como clientes cambia la forma de actuar de las Administraciones públicas. Ya no sólo tienen el papel de proveedor de servicios públicos sino que además tienen que tener en cuenta el grado de satisfacción de la ciudadanía respecto de éstos. A su vez la ciudadanía va adquiriendo un papel más participativo en los asuntos que forman parte de la agenda pública (Mesa Del Olmo, 2007).

Cada vez más las administraciones se están enfrentando al reto de las transformaciones que las TIC están produciendo en la sociedad. La mayoría de las Administraciones públicas se encuentran en proceso de incorporar en su relación con los ciudadanos, y en general en todos los procesos internos, tecnologías avanzadas con el único fin de otorgar una información amplia y de fácil acceso, proporcionando así en lo posible un mejor servicio (Casillas, Mesa y Ramilo, 2005).

Visto lo anterior la Administración electrónica, representa la rápida difusión de las TIC asociada a la agenda de la modernización de la gestión de las administraciones públicas. Además, lleva implícito la oportunidad para rediseñar el gobierno y ofrecer una nueva forma de gobernar orientada por completo al ciudadano, abogando, además, por un cambio tecnológico y de las estructuras tradicionales de los estados (Martínez, 2007).

En efecto, se está produciendo una extensión de las TIC a todos los ámbitos administrativos. Sin embargo, conviene señalar que son varios los conceptos que abordan el uso de las TIC como un fenómeno tecnológico y de gestión. Así por ejemplo, como mencionábamos en líneas anteriores, existen diferentes términos los cuales es necesario delimitar, tales como: gobierno electrónico, Administración electrónica y democracia electrónica ${ }^{3}$.

3 La investigación jurídica en el ámbito público vinculado a los fenómenos de las nuevas tecnologías sé topa con otro problema: vamos a remolque de la realidad y de los estudios de otras disciplinas que se adecuan mejor a estas parcelas de análisis. En el ámbito de las nuevas tecnologías, el derecho o bien responde con proclamaciones principales genéricas para intentar adecuarse a realidades muy variables, o bien responde con normativa con escaso rango, pero mayor concreción, que no obstante, es continuamente modificada para recibir los últimos cambios y tendencias de una realidad que se va construyendo, día a día. Este proceso de evolución de las nuevas tecnologías y su empelo dinámico en extremo lleva a que la importancia del derecho como conformador de esa realidad misma sea bastante escasa. Más bien sucede lo contrario, son otros factores de naturaleza política, sociológica, técnica o económica los que conforman dicha realidad y el derecho pasa a ser en la mayoría de las 
El gobierno en tanto que actúa como órgano de dirección política procede y se configura como algo distinto a la administración, manifestándose a través de los actos políticos o actos de gobierno. La Administración no es más que un instrumento del gobierno para la elaboración y materialización de sus políticas, para atender al interés general en la forma que desde su visión política considerada más atinada por lo que la administración, como burocracia técnica, debe carecer cualquier tipo de posición política propia de lo que se deduce, un primer aspecto de los principios de neutralidad en el ámbito de la actividad administrativa.

La Administración, con independencia de la orientación política que se le pueda otorgar por el Gobierno que se trate, tiene que servir, atender y gestionar intereses generales de los ciudadanos. El Gobierno a la hora de dirigir la administración deberá observar las reglas y los procedimientos previamente establecidos; es decir, con plena sujeción a la Ley y al Derecho.

Esto queda establecido desde el punto de vista normativo en el Artículo 103.1 de la Constitución Española al señalar que la Administración Pública sirve con objetividad a los intereses generales y actúa de acuerdo con los principios de eficacia, jerarquía, descentralización, desconcentración y coordinación con sometimiento pleno a la ley y al Derecho.

El artículo 3.3 de la LRJAP y PAC señala que bajo la dirección del gobierno de la nación, de los órganos de gobierno de las comunidades autónomas y de las correspondientes entidades que integran la Administración local, la Administración pública respectiva se desarrolla para alcanzar los objetivos que establecen las leyes y el resto del ordenamiento jurídico.

Partiendo de algunas de las diferencias entre Administración y Gobierno se tiene una aproximación y delimitación de lo que podemos denominar gobierno y Administración electrónica. Se denomina gobierno electrónico a la utilización de las TIC para mejorar y optimizar la prestación de los servicios públicos y la participación ciudadana en procesos de consulta y de elaboración de políticas públicas ${ }^{4}$.

El gobierno electrónico se define como el uso eficaz de la tecnología con el fin de facilitar una comunicación que permita la toma de decisiones tanto a representantes como a ciudadanos en cuestiones que afecten al bien común con el objeto de aumentar la calidad y honestidad del sistema. La Administración electrónica es sólo la versión

ocasiones mero receptor tardío de tales influjos. Todo parece indicar que tales perspectivas: ciencia política, ciencia de la administración, económicas, etc. Se adecuan mejor a la investigación en estas cuestiones, por sus menores dificultades de trabajar sobre esta actualidad y su mayor flexibilidad metodológica para actuar sobre esta. La consecuencia no es otra que la presencia discreta de la literatura jurídica en ámbitos como el de las libertades públicas y nuevas tecnologías, y en especial con parcelas, como las llamados, Gobierno, Participación, y democracia electrónicas(Cotino,2004).

4 Partiendo de este concepto se derivan tres dimensiones importantes en el concepto de gobierno electrónico, en los cuales se encuentran la e-administración, es decir los gobiernos como prestadores de servicios; la e- democracia, en el sentido de que los gobiernos locales actúan como promotores de la democracia en el ámbito local; y la e-gobernanza, referido a su papel como elaboradores de políticas en el ámbito local (Mesa Del Olmo2007). 
automatizada de los servicios públicos que el gobierno presta a los ciudadanos y definen como el uso eficiente de la tecnología en la administración y en la gestión de servicios gubernativos para abaratarlos y hacerlos más productivos.

En el caso de la democracia electrónica cuenta con varios sinónimos tales como: democracia digital, teledemocracia, ciberdemocracia, democracia virtual, etc. Todos estos conceptos aunque con diferentes matices hacen referencia al reconocimiento de que las nuevas redes de telecomunicaciones, micro electrónica y ordenadores, contribuyen al desempeño de funciones esenciales para los procesos democráticos, tales como proveer información, permitir la comunicación entre los distintos agentes políticos, articular el interés en torno a determinados asuntos y participar en el proceso de toma de decisiones mediante la deliberación y el voto (Bermejo, 2003).

Por lo tanto la democracia electrónica expresa la aplicación de las tecnologías a la participación ciudadana en los procesos democráticos. El rol de las TIC en los procesos de participación ciudadana es decisivo. Las TIC pueden servir para impulsar y fortalecer la democracia local. A través de ella se trata de ofrecer información de carácter institucional y de los diferentes servicios a través de las páginas web, foros chats etc. De este modo contribuyen a extender la información, participación e intercambio de ideas hasta alcanzar la votación electrónica y desarrollar procesos más plurales de discurso y participación.

Incluso existen dentro de los grupos que defienden a la ciberdemocracia ${ }^{5}$, las posibilidades tecnológicas existentes, resumiendo sus virtudes como:

- Mayor eficacia y facilidad de acceso a la información (transparencia).

- Las TIC pueden ser utilizadas para medir las preferencias de los ciudadanos en las democracias representativas (información, deliberación, debate y voto).

- Se pueden crear nuevas posibilidades organizativas a través de grupos de discusión específicos, reduciendo costes.

- La RED es una metáfora o una precursora de una nueva comunidad política anárquica en que las identidades vinculadas al territorio a intereses sectoriales están socavadas, y emergen nuevas formas de políticas libres de coerción estatal (comunicación más horizontal que vertical).

- La audiencia puede responder inmediatamente a la información (interactividad).

- Existe menos posibilidad de establecer censura por parte de los políticos, periodistas, parlamentarios, partido.

- Se produce mayor eficiencia en la provisión de servicios, ya que las nuevas tecnologías permite prestar los servicios al ciudadano/consumidor según sus necesidades/deseos usando instrumentos como votaciones, referendo, y revisiones de la actuación pública (lo que enlaza con el NGP).

- Puede resolver en la práctica los dilemas de la democracia representativa.

5 La ciberdemocracia, tienen varios sinónimos como "democracia digital, "democracia virtual" o "democracia de la sociedad de la información, término que se refiere a las implicaciones de las nuevas tecnologías sobre el proceso político 
Con las delimitaciones vistas anteriormente, podemos afirmar que cada uno de los conceptos tiene como denominador común el empleo de las TIC para el desarrollo de acciones características de la administración pública y también con los procesos políticos característicos del gobierno. Incluso podemos afirmar que en el caso de los conceptos de gobierno electrónico y Administración electrónica, términos que aplicados en Latinoamérica y Europa respectivamente, tal como lo apuntábamos en primeras líneas, vienen a significar lo mismo.

Así queda de manifiesto, tanto en la Carta Iberoamericana de gobierno electrónico (Carta Iberoamericana de gobierno electrónico, 2007) al definirlo como el uso de las tecnologías de la información y de la comunicación en los órganos de la administración para mejorar la información y los servicios ofrecidos a los ciudadanos, orientar la eficacia y la eficiencia de la gestión pública e incrementar sustantivamente la transparencia del sector público y la participación de los ciudadanos; como también en la Comunicación de la Comisión de las Comunidades Europeas COM ( 2003, 567 final), que define a la administración electrónica como el uso de las tecnologías de la información y las comunicaciones en las administraciones públicas, combinado con cambios organizativos y nuevas aptitudes, con el fin de mejorar los servicios públicos y los procesos democráticos y reforzar el apoyo a las políticas públicas.

\subsection{La Administración Electrónica en la Unión Europea}

La Unión Europea (UE) a partir de 1999, ha impulsado proyectos tecnológicos de las administraciones públicas orientados a la mejora de la prestación de servicios públicos electrónicos, incentivando la utilización de las TIC en la gestión de los servicios de las administraciones. Todas ellas se han recogido bajo el denominador común de e-Europe.

En el Consejo de Feira celebrado los días 19 y 20 de junio de 2000, se aprobó el Plan de Acción e-Europe(2002) (Consejo y la Comisión Europea para el Consejo Europeo, 2000), encaminado a hacer realidad este objetivo a través de tres ejes de actuación:

- Una Internet más rápida, barata y segura.

- Invertir en las personas y en la formación.

- Estimular el uso de Internet.

Dentro de este último eje, las administraciones públicas tienen responsabilidad directa sobre tres de las cinco iniciativas que lo componen:

- Administración en línea: ofrecer acceso electrónico a los servicios públicos.

- Sanidad en línea.

- Contenidos digitales europeos para las redes mundiales.

La iniciativa e-Europe (2002) se fija como objetivo facilitar a los ciudadanos un acceso fácil a la información pública esencial, así como fomentar la interacción en línea entre ciudadanos y gobiernos. La mejora de la eficiencia del sector público exige 
un replanteamiento de la organización interna y de los intercambios electrónicos entre instituciones.

Se plantearon siete acciones para impulsar la iniciativa e-Europe (2002), en relación a la Administración en línea, que son:

- Información pública esencial en línea, incluida la información jurídica, administrativa, cultural, medioambiental y sobre tráfico.

- Los Estados miembros deben garantizar el acceso electrónico generalizado a los principales servicios públicos básicos.

- Procedimientos administrativos simplificados en línea para las empresas (por ejemplo, procedimientos rápidos para la creación de empresas).

- Desarrollo de un planteamiento coordinado acerca de la información sobre el sector público, incluida la información a nivel europeo.

- Fomento de la utilización de programas de fuentes abiertas en el sector público y de las mejores prácticas de Administración electrónica mediante el intercambio de experiencias en toda la Unión (a través de los Programas IST e IDA).

- Fomento de la utilización de la firma electrónica en el sector público.

- Todos los trámites principales con la Comisión Europea deben facilitarse en línea (por ejemplo, en lo que se refiere a financiación, contratos de investigación, contratación de personal y adjudicación de contratos).

Como continuación del Plan de Acción e-Europe (2002), el Consejo Europeo aprobó en Sevilla en los días 21 y 22 de junio de 2002, el nuevo Plan de Acción e-Europe 2005 (Comunicado de la Comisión al Consejo, 2002), al haberse alcanzado a esa fecha la práctica totalidad de los objetivos del Plan e-Europe 2002 y tener previsto su pleno cumplimiento para finales de 2002.

En el nuevo Plan de Acción e-Europe 2005 se fijó la prioridad de estimular los servicios, aplicaciones y contenidos que creen nuevos mercados, reduzcan los costes $\mathrm{y}$, como consecuencia, incrementen la productividad en toda la economía.

Los objetivos fijados en e-Europe 2005 son de dos tipos:

- Servicios, aplicaciones y contenidos. Incluye tanto los servicios públicos en línea como los negocios electrónicos.

- Infraestructura de banda ancha y seguridad.

Fijándonos en el objetivo de los servicios, en e- Europe 2005 se propone:

- Servicios públicos en línea modernos.

- Entorno dinámico de negocios electrónicos.

El nuevo plan i-2010 sobre "Una Sociedad de la Información europea para el crecimiento y el empleo" (Comunicado de la Comisión al Consejo, 2005, 229 final), presentado el 1 de junio de 2005 durante la presidencia irlandesa, es continuación de los Planes de Acción e-Europe y se integra en la estrategia de Lisboa renovada en favor del crecimiento y el empleo i-2010 insiste en la investigación y el uso de las TIC para generar crecimiento y empleo, haciendo especial énfasis en que los beneficios de las TIC proceden de su incorporación a productos y servicios y de la adopción de 
nuevos modelos de negocio, del cambio en las organizaciones y de la cualificación, además de la coordinación en puntos esenciales, tales como la interoperabilidad, la seguridad y fiabilidad, la gestión de identidades, la gestión de derechos y la facilidad de uso.

El Plan i-2010 tiene tres objetivos básicos:

- Un Espacio Único Europeo de la Información que ofrezca comunicaciones de banda ancha asequibles y seguras, contenidos ricos y diversificados y servicios digitales.

- Rendimiento de nivel mundial en la investigación y la innovación en el ámbito de las TIC, acercando así a Europa a sus principales competidores.

- Una Sociedad de la Información que sea incluyente, ofrezca servicios públicos de gran calidad y promueva la calidad de vida.

Este tercer objetivo es el que más se ajusta al desarrollo de la e-Administración al pretender que los servicios públicos sean mejores, más rentables y más accesibles y que mejore la calidad de vida de los ciudadanos europeos.

El 19 de mayo de 2006, se presentó el primer informe anual de la iniciativa i-2010 (Comunicación de la Comisión al Consejo). Este informe examina los logros del primer año de la iniciativa i- 2010 y pone al día las acciones i-2010 para el periodo 2006-2007. Esta puesta al día se basa en el documento de trabajo de la Comisión sobre el mismo tema que repasa las acciones claves incluidas en la iniciativa i-2010 con la perspectiva de los progresos.

\subsection{La Administración Electrónica en España}

El proceso de implantación y desarrollo de la administración electrónica en España se inicia con la creación en 1983 del Consejo Superior de Informática que dio lugar a diferentes comisiones interministeriales que operarían dentro de este campo. Posteriormente, se firma el Acuerdo del Consejo de Ministros del 15 de noviembre de 1991 en el que se definen los objetivos de la modernización y se insta a los Ministerios a elaborar proyectos concretos de mejora para 1992, en los que apuesta por la utilización de la informática como factor del cambio.

Con la implantación de las nuevas tecnologías, se pretende establecer una estrategia de cambio en las estructuras organizativas, en los procedimientos de actuación y en el perfil y cualificación de los recursos humanos.

A partir de ese momento se ponen en marcha programas o proyectos con el fin de incorporar las TIC como parte de la modernización de las Administraciones Públicas españolas ${ }^{6}$. Pero sin duda el punto de arranque fundamental lo dio la Comisión

6 El proyecto PRISMA 93, iniciado a finales de 1990, está dirigido a identificar aquel conjunto de proyectos de sistemas y tecnologías de la información que tengan mayor impacto en la modernización administrativa teniendo en cuenta su posible engarce con los de otras Administraciones europeas una vez se establezca el marco del Acta Única de 1993. El segundo de estos proyectos es el proyecto ATRIO (Almacenamiento, Tratamiento y Recuperación de Oficinas) que es una idea lanzada a finales de 1989 por el CSI, con el objeto de promover la realización de varios prototipos de la oficina administrativa del futuro en la que todos los papeles que entren en la organización sean tratados automáticamente en el camino hacia una oficina con menos papeles. 
Europea con sus diferentes programas, e-Europe 2000 y e-Europe 2005, los cuales han guiado las políticas de la Sociedad de la Información y del Gobierno electrónico en España.

A modo de referencia, algunos de los objetivos resumidos dentro de este Plan e-Europe 2005 (Una sociedad de la información para todos) contenía los siguientes extremos: unos servicios públicos en línea modernos; una administración electrónica; unos servicios electrónicos de aprendizaje; unos servicios electrónicos de salud; un entorno dinámico de negocios electrónicos. Y para hacer todo ello posible, un acceso de banda ancha ampliamente disponible y a precios competitivos y una infraestructura de información segura (Mesa Del Olmo, 2007).

Otros de los planes impuestos por el Gobierno de España en 1999 fue el Plan Info XXI: sociedad de la información para todos para el período 2000-2003. Este Plan no consistió sino en la translación a las administraciones españolas del programa e-Europe con objetivos en diferentes campos (educación, creación de empleo, innovación, promoción de la eficiencia, cohesión social, calidad de vida, cultura e imagen en el exterior) (Sancho, 2005).

Posteriormente se crea la Comisión Soto con el fin de impulsar proyectos de la sociedad de la información en las administraciones públicas. Una de las recomendaciones que elaboró dicha comisión consistió en crear un plan de choque al que denominaron Espana.es.

En el año 2005 el Consejo Superior de Informática se transforma en el Consejo Superior de Administración Electrónica ${ }^{7}$, como órgano colegiado dependiente del Ministerio de Administraciones Públicas y que se encarga de la elaboración y aplicación de la línea estratégica de gobierno en materia de administración electrónica y centraliza pues estos asuntos.

En ese mismo año el Gobierno de España puso en marcha una estrategia conocida como Plan Ingenio con el fin de acortar la brecha tecnológica con los países más avanzados. Las medidas relacionadas con la e- Administración son impulsadas tanto por el Ministerio de Administraciones Públicas como por el Ministerio de Industria, Turismo y Comercio.

El Plan Ingenio o compromiso Ingenio $2010^{8}$, nombre con el que se le conoce oficialmente se apoya en tres programas: Cenit, Consolider y Avanza. Este último tiene como objetivo la convergencia con la UE en materia de Sociedad de la Información. Además, es el que recoge las acciones, entre otras muchas, encaminadas a impulsar la e-Administración en una de sus cuatros líneas estratégicas.

7 El Consejo Superior de Administración Electrónica es creado por el Real Decreto 589/2002 de 20de mayo, es el órgano encargado de la preparación, la elaboración, el desarrollo y la aplicación de la política y la estrategia del Gobierno en materia de tecnologías de la Información, así como el impulso e implantación de la administración electrónica en la Administración General del Estado. 
El Área de Servicios Públicos Digitales ${ }^{9}$, pretende conseguir una e- Administración plenamente desarrollada por lo cual se ha propuesto los objetivos siguientes para sus acciones concretas:

- Garantizar el derecho de ciudadanos y empresas a relacionarse electrónicamente con las administraciones públicas, por lo cual la totalidad de los servicios prestados por las administraciones deberán ofrecer en 2010 como mínimo algunas de sus prestaciones a través de Internet.

- Establecer los mecanismos para que la oferta de servicios en línea se corresponda con la demanda existente, creando un catálogo claro de servicios electrónicos.

- Garantizar la existencia de canales adecuados para que todos los ciudadanos y empresas puedan hacer uso de los servicios proporcionados por las Administraciones Públicas.

- Modernizar las Administraciones Públicas españolas en términos de mejora de la calidad, agilidad y rendimiento de los servicios a los ciudadanos, eficiencia en el uso de los recursos públicos, reducción de costes, satisfacción de los usuarios, integración interdepartamental y simplificación administrativa.

- Crear estructuras de cooperación entre las distintas administraciones públicas (Administración General del Estado, comunidades autónomas y entes locales).

Para llevar adelante los objetivos de esta área de actuación se han establecido mecanismos de colaboración entre:

- El Ministerio de Administraciones Públicas, como responsable del desarrollo de la e- Administración en la Administración General del Estado, así como de la cooperación con el resto de las administraciones públicas en dicha materia.

- Las comunidades autónomas y entidades locales, responsables de desarrollar la e-Administración en sus ámbitos respectivos.

- El Ministerio de Industria, Turismo y Comercio, como responsable de las políticas de impulso a la Sociedad de la Información, deberá apoyar y complementar los esfuerzos realizados por aquellas.

El mayor impulso dado por el gobierno hacia la e- Administración se concreta con el llamado Plan Moderniza (Consejo de Ministros, 2005). El Consejo de Ministros aprobó el Plan Moderniza, con el objetivo de dar impulso a los servicios públicos durante este periodo. Con este Plan la Administración pretende mejorar su organización y los servicios públicos ofrecidos a los ciudadanos, mediante la aplicación de un modelo diferente de Administración electrónica. Este Plan se complementa con la puesta en marcha de:

9 Servicios Públicos Digitales Plan Avanza. http://www.planavanza.es/AreasActuacion/ ServiciosPúblicos/Objetivos/Objetivos.htm. 
- El estatuto básico del empleado público.

- La ley de la Administración electrónica que reconoce el derecho de los ciudadanos a relacionarse telemáticamente con las Administraciones y que ha sido remitida a finales de noviembre por el Consejo de Ministros al Parlamento para que siga los trámites de su aprobación.

- $\quad$ La Red de de Oficinas integradas con las comunidades autónomas y los ayuntamientos.

- La unificación de los teléfonos de atención ciudadana de la AGE en el número 060.

Además, el Plan Moderniza ha originado la creación del Observatorio de Calidad de los Servicios Públicos como instrumento para proponer iniciativas de mejora. Asimismo, el Plan Moderniza ha promovido un plan especial de medidas y de reforma de la Administración periférica, otro de modernización tecnológica y simplificación administrativa y un tercero para promocionar la transparencia y la participación de la Administración.

Con el Plan Moderniza se propone introducir una mayor transparencia y calidad en la gestión de los servicios públicos, con el objetivo de solucionar los problemas de los ciudadanos a través de medidas como la simplificación de los procesos internos, el impulso a la Administración electrónica y la motivación de unos empleados más cualificados. Los cuatro meta proyectos del Plan Conecta (Certifica, eDNI, Ciudadano.es y Simplifica) y el Plan Departamental MAP en Red, han quedado integrados en el nuevo Plan Moderniza.

Precisamente uno los trabajos que se tenían como primarios a llevar a cabo por medio del Plan Moderniza la medida de elaboración de la Ley de administración electrónica y que debía abarcar entre otros objetivos el reconocimiento de los derechos y deberes de los ciudadanos en su relación telemática con las administraciones. En el siguiente capítulo analizaremos con mayor extensión todo lo relacionado con esta Ley, que ya en la actualidad está vigente.

\section{MARCO NORMATIVO DE LA ADMINISTRACIÓN ELECTRÓNICA EN ESPAÑA}

En España, el impulso de la Administración en el empleo y la aplicación de procedimientos electrónicos, informáticos y telemáticos en el desarrollo de la Administración electrónica y su actividad, son notorios y se hacen patentes en la legislación, como: la Ley 30/1992; Ley de Agencias Estatales para la mejora de los Servicios Públicos; R.D. 14/99 de Firma electrónica; R. D. 522/2006 de 28 de abril que suprime la aportación de fotocopias de documento de identidad en la Administración; R.D.523/2006 que suprime la exigencia de aportar el certificado de empadronamiento y la Ley 11/2007 de acceso electrónico de los ciudadanos a los Servicios Públicos; entre otras (Barriuso, 2007. p. 27). 


\subsection{Ley 30/1992, de 26 de noviembre, de Régimen Jurídico de las Administraciones Públicas y del Procedimiento Administrativo Común}

La Ley 30/1992 incluyó en su texto inicial un régimen de cabecera, contenido en el Art. 45, dirigido a regular genéricamente el empleo de medios electrónicos, informáticos y telemáticos por las Administraciones Públicas. El artículo 45.1 señala que las Administraciones Públicas impulsarán el empleo y aplicación de las técnicas y medios electrónicos, informáticos y telemáticos, para el desarrollo de su actividad y el ejercicio de sus competencias, con las limitaciones que a la utilización de estos medios establecen la Constitución y las Leyes.

Asimismo establece que los ciudadanos podrán relacionarse con las Administraciones Públicas para ejercer sus derechos a través de técnicas y medios electrónicos, informáticos o telemáticos con respecto de las garantías y requisitos previstos en cada procedimiento, pero siempre que sea compatible con los medios técnicos con los que dispongan las Administraciones Públicas (Art. 45.2).

Este mismo precepto en el apartado 3 sigue señalando la garantía de identificación y el ejercicio de la competencia por el órgano competente, cuando los procedimientos se tramiten y terminen en soporte informático; en tanto, que en el apartado 4 se refiere a la aprobación de lo que podríamos denominar software que habrá de ser utilizado por las Administraciones Públicas.

Por último, se señala en el apartado 5 que los documentos emitidos, cualquiera que sea su soporte, por medios electrónicos, informáticos o telemáticos por las Administraciones Públicas, o los que éstas emitan como copias de originales almacenados por estos mismos medios, gozarán de la validez y eficacia de documento original siempre que quede garantizada su autenticidad, integridad y conservación y, en su caso, la recepción por el interesado, así como el cumplimiento de las garantías y requisitos exigidos por ésta u otras Leyes.

Existen otros dos preceptos de la Ley 30/1992, como el Art. 38 en el que se le agrega un apartado 9, con la Ley 24/2001 en el que se regula lo referente a la creación de registros telemáticos para la recepción o salida de solicitudes, escritos y comunicaciones que se transmitan por medios telemáticos, con sujeción a los requisitos establecidos en el apartado 3 de este mismo artículo. Asimismo, se establece que los registros telemáticos sólo estarán habilitados para la recepción o salida de las solicitudes, escritos y comunicaciones relativas a los procedimientos y trámites de la competencia del órgano o entidad que creó el registro y que se especifiquen en la norma de creación de éste, así como que cumplan con los criterios de disponibilidad, autenticidad, integridad, confidencialidad y conservación de la información que igualmente se señalen en la citada norma.

Finalmente, el tercero de los preceptos que dentro de la Ley 30/1992 hace referencia a uno de los componentes de la Administración electrónica, es el Art. 59 al cual también le fue agregado un apartado 3 con la Ley 24/2001, referente a la 
notificación de los actos administrativos mediante el uso de medios telemáticos. Se indicaba que en esos casos, la notificación se entenderá practicada a todos los efectos legales en el momento en que se produzca el acceso a su contenido en la dirección electrónica. Y se continuaba señalando que, existiendo constancia de la recepción de la notificación en la dirección electrónica, transcurrieran diez días naturales sin que se acceda a su contenido, se entenderá que la notificación ha sido rechazada con los efectos previstos en el siguiente apartado, salvo que de oficio o a instancia del destinatario se compruebe la imposibilidad técnica o material del acceso.

Estos preceptos significaban una aproximación a la Administración electrónica. Dicha aproximación era más bien facultativa, ya que la aplicación de varias de las medidas contempladas no era obligatoria. Además, resulta importante destacar que en el caso de los apartados 9 del Art. 38, los apartados 2, 3 y 4 del Art. 45 y 3 del Art. 59 han sido derogados y además superados por la Ley 11/2007, el cual analizaremos a continuación ${ }^{10}$.

\subsection{Ley 11/2007 de 22 de junio, de acceso electrónico de los ciudadanos a los Servicios Públicos}

Desde mediados del 2005, el Ministerio de Administraciones Públicas inició los primeros borradores de la llamada entonces Ley de Administración Electrónica. Desde los primeros momentos se quería una ley que sirviera no sólo para que las administraciones puedan ofrecer los servicios, sino para que los ciudadanos tengan el derecho de exigirlos y puedan hacer sus trámites través de la Red y los procedimientos telemáticos ${ }^{11}$.

Recordemos que en la LRJPAC, los preceptos que guardan relación con la Administración electrónica venían a ser insuficientes con el desarrollo de la misma, porque eran de carácter facultativo y dejaban en manos de las propias Administraciones determinar si los ciudadanos van a poder de modo efectivo, o no, relacionarse por medios electrónicos con ellas, según que éstas quieran poner en pie los instrumentos necesarios para esa comunicación con la Administración. Por ello,

10 Para Julián Valero, el desarrollo normativo, tanto legal como reglamentario que ha tenido la legislación básica anterior a la LAECSP se ha caracterizado por la timidez a la hora de reconocer derechos a los ciudadanos y, por consiguiente, para establecer obligaciones claras y terminantes

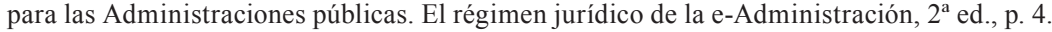

11 Los primeros borradores de la ley recogían ya los resultados de la tercera Conferencia Ministerial sobre e-Government de la Unión Europea celebrada en Manchester los días 24 y 25 de noviembre de 2005. En la Declaración final de la Conferencia se recoge la propuesta del Gobierno español de establecer criterios objetivos para evaluar el grado de avance de la Administración electrónica en cada país, se fija para 2010 la posibilidad de que todos los ciudadanos comunitarios puedan acceder a los servicios telemáticos públicos de cualquier estado de la UE con todas las garantías de seguridad, que en todos los estados miembros sea posible antes de 2010 realizar, a través de Internet, al menos, el 50\% de los trámites administrativos y que la Administración electrónica potencie su papel como instrumento de integración social, en la medida que elimina la discriminación de acceso a los distintos servicios públicos. 
esta Ley pretende dar el paso del podrán por el deberán (Boletín Oficial de las Cortes Generales, 2007).

En virtud de lo anterior, la LAECSP viene a consagrar el derecho básico de todos los ciudadanos a relacionarse electrónicamente con las Administraciones, así como la obligación de éstas a garantizarlo. La trascendencia de esa nueva declaración es manifiesta, pues refleja la innovación que esta norma proyecta sobre instituciones tradicionales de la acción administrativa, por lo que, de los cambios que implica en los modos de actuar de la Administración se originarán importantes consecuencias para la los ciudadanos (Blasco, 2007).

La LAECSP ha de tener un impacto importante tanto en lo particular, en cuanto a la regulación de la Administración electrónica como, en general, a su desarrollo en España. La Ley establece en su exposición de motivos que el servicio al ciudadano exige consagrar su derecho a comunicarse con las Administraciones por medios electrónicos. La contrapartida de ese derecho es la obligación de éstas de dotarse de los medios y sistemas electrónicos para que ese derecho pueda ejercerse (Boletín Oficial de las Cortes Generales, 2007).

Esa es una de las grandes novedades de la Ley: pasar de la declaración de impulso de los medios electrónicos e informáticos, que se concretan en la práctica en la simple posibilidad de que algunas Administraciones, o algunos de sus órganos, permitan las comunicaciones por medios electrónicos, a que estén obligadas a hacerlo porque la Ley reconoce el derecho de los ciudadanos a establecer relaciones electrónicas.

La Ley consagra la relación con las Administraciones Públicas por medios electrónicos como un derecho de los ciudadanos y como una obligación correlativa para tales Administraciones. El reconocimiento de tal derecho y su correspondiente obligación se erigen así en el eje central del proyecto de Ley.

\subsection{Objeto y Finalidades de la LAECSP}

El Art. 1 señala que el objeto de la LAECSP es que reconoce el derecho de los ciudadanos a relacionarse con las Administraciones Públicas por medios electrónicos y regula los aspectos básicos de la utilización de las tecnologías de la información en la actividad administrativa, en las relaciones entre las Administraciones Públicas, así como en las relaciones de los ciudadanos con las mismas con la finalidad de garantizar sus derechos, un tratamiento común ante ellas y la validez y eficacia de la actividad administrativa en condiciones de seguridad jurídica.

Asimismo señala que cuando las Administraciones Públicas utilicen las tecnologías de la información de acuerdo con lo dispuesto en ésta misma Ley, deberá asegurar la disponibilidad, el acceso, la integridad, la autenticidad, la confidencialidad y la conservación de los datos, informaciones y servicios que gestionen en el ejercicio de sus competencias.

El Art. 3 de la LAECSP enumera muy claramente cuáles son sus fines: 
- Facilitar el ejercicio de derechos y el cumplimiento de deberes por medios electrónicos.

- Facilitar el acceso por medios electrónicos de los ciudadanos a la información y al procedimiento administrativo, con especial atención a la eliminación de las barreras que limiten dicho acceso.

- Crear las condiciones de confianza en el uso de los medios electrónicos, estableciendo las medidas necesarias para la preservación de la integridad de los derechos fundamentales, y en especial los relacionados con la intimidad y la protección de datos de carácter personal, por medio de la garantía de la seguridad de los sistemas, los datos, las comunicaciones, y los servicios electrónicos.

- Promover la proximidad con el ciudadano y la transparencia administrativa, así como la mejora continuada en la consecución del interés general.

- Contribuir a la mejora del funcionamiento interno de las Administraciones Públicas, incrementando la eficacia y la eficiencia de las mismas mediante el uso de las tecnologías de la información, con las debidas garantías legales en la realización de sus funciones.

- Simplificar los procedimientos administrativos y proporcionar oportunidades de participación y mayor transparencia, con las debidas garantías legales.

- Contribuir al desarrollo de la sociedad de la información en el ámbito de las Administraciones Públicas y en la sociedad en general.

\subsection{Aspectos esenciales de la LAECSP}

Los Aspectos a destacar de la LAECSP se pueden resumir de la siguiente manera:

- Reconoce el derecho de los ciudadanos a la relación electrónica con las Administraciones y fija un plazo (hasta diciembre de 2009) para que las Administraciones habiliten el acceso electrónico a todos sus procedimientos administrativos.

- Establece los mecanismos necesarios para garantizar el tratamiento común de los ciudadanos por parte de todas las Administraciones.

- Regula los mecanismos imprescindibles paragarantizar la interoperabilidad entre las Administraciones, para que los documentos electrónicos emitidos por cualquiera de ellas puedan ser presentados y usados por cualquier otra.

- La Ley define un catálogo amplio de derechos para los ciudadanos.

- Para velar por el cumplimiento de estos derechos, la Ley crea la figura del Defensor del usuario de la Administración Electrónica, que anualmente elevará un informe al Consejo de Ministros con el análisis de las quejas y sugerencias recibidas, proponiendo actuaciones y medidas correctoras.

Ahora bien, con el objeto de dotar de las garantías jurídicas necesarias, la Ley define el régimen jurídico de la Administración electrónica: 
- Regula el concepto de "sede electrónica", responsabilizándose la Administración de lo que se pública y de los trámites que se realizan.

- Establece las formas válidas de identificación y autenticación, dando un papel relevante a la utilización del DNI electrónico.

- Mejora la regulación de los registros, comunicaciones y notificaciones electrónicas y obliga a las Administraciones a crear los registros para recibir cualquier tipo de documento dirigido a ellas.

- Regula la validez del documento y expediente electrónico y de sus copias.

La Ley, también define la utilización de medios electrónicos en la gestión de los procedimientos, prestando una atención especial al rediseño de los procedimientos y a su simplificación, e introduce el concepto de "actuación administrativa automatizada".

Otro de los aspectos en los cuales la Ley presta especial atención es a los mecanismos de cooperación entre Administraciones para garantizar la interoperabilidad de los sistemas y aplicaciones desarrolladas y la reutilización de aplicaciones y la transferencia de tecnologías entre éstas, esto al considerar a España un Estado altamente descentralizado y con lo cual se hace necesaria la utilización de estos mecanismos.

Asimismo, la Ley introduce algunos cambios necesarios para hacer posible las reuniones de órganos colegiados por medios electrónicos, impulsar la formación permanente en la utilización de medios electrónicos y el teletrabajo en la Administración General del Estado. Desatacan asimismo en esta Ley la creación de una Red de Comunicaciones entre todas las Administraciones Públicas, la denominada red SARA, y la Red integrada de Atención al ciudadano cuyo actual embrión es la Red 060.

\section{DE LA DEFENSA DE LOS DERECHOS DE LOS CIUDADANOS ANTE LA ADMINISTRACIÓN ELECTRÓNICA}

En el presente capítulo se abordará lo relacionado a la defensa de los derechos de los ciudadanos que ante la Administración electrónica regula la misma LAECSP, e incluso aquellos que se mencionan en la Ley 30/1992. Por lo tanto, debemos dejar definido el concepto de ciudadano y señalar cuáles son esos derechos garantizados a los ciudadanos.

La LAECSP en su anexo de definiciones en el inciso h señala define claramente que ciudadano es cualquier persona física, persona jurídica o ente sin personalidad que se relacione, o sea susceptible de relacionarse, con las Administraciones Públicas.

Ahora que ya se tiene establecido quien es el ciudadano, sigue el señalar cuáles son esos derechos que deben garantizarse ante la administración electrónica. Pues bien, la LAECSP en el Título Primero están recogidos los derechos de los ciudadanos en sus relaciones con las Administraciones Públicas a través de medios electrónicos, 
reconociendo además los derechos previstos 35 de la Ley 30/1992 $2^{12}$.

En la LRJ-PAC en el Título IV sobre la actividad de las Administraciones Públicas, en el artículo 35 recoge los derechos de los ciudadanos en sus relaciones con la Administración Pública. Estos derechos, que a continuación se mencionan son:

a. A conocer, en cualquier momento, el estado de la tramitación de los procedimientos en los que tengan la condición de interesados, y obtener copias de documentos contenidos en ellos.

b. A identificar a las autoridades y al personal al servicio de las Administraciones Públicas bajo cuya responsabilidad se tramiten los procedimientos.

c. A obtener copia sellada de los documentos que presenten, aportándola junto con los originales, así como a la devolución de éstos, salvo cuando los originales deban obrar en el procedimiento.

d. A utilizar las lenguas oficiales en el territorio de su Comunidad Autónoma, de acuerdo con lo previsto en esta Ley y en el resto de Ordenamiento Jurídico.

e. A formular alegaciones y a aportar documentos en cualquier fase 32 tenidos en cuenta por el órgano competente al redactar la propuesta de resolución.

f. A no presentar documentos no exigidos por las normas aplicables al procedimiento de que se trate, o que ya se encuentren en poder de la Administración actuante.

g. A obtener información y orientación acerca de los requisitos jurídicos o técnicos que las disposiciones vigentes impongan a los proyectos, actuaciones o solicitudes que se propongan realizar.

h. Al acceso a los registros y archivos de las Administraciones Públicas en los términos previstos en la Constitución y en ésta u otras Leyes.

i. A ser tratados con respeto y deferencia por las autoridades y funcionarios, que habrán de facilitarles el ejercicio de sus derechos y el cumplimiento de sus obligaciones.

j. A exigir las responsabilidades de las Administraciones Públicas y del personal a su servicio, cuando así corresponda legalmente.

k. Cualesquiera otros que les reconozcan la Constitución y las Leyes.

Los derechos recogidos en la LAECSP en su Artículo 6 son:

1. Obtener informaciones, realizar consultas y alegaciones, formular solicitudes, manifestar consentimiento, entablar pretensiones, efectuar

12 Agustí Cerrillo (2008a) llama a estos derechos instrumentales o auxiliares y los clasifica en: a) derechos relacionados con los medios electrónicos; b) derechos relacionados con el procedimiento administrativo electrónico, que son los referidos al art. 35 de la LRJ-PAC; c) los derechos relacionados con la seguridad de las transacciones electrónicas; y d) los derechos de una información y servicios públicos de calidad (p. 59-63). 
pagos, realizar transacciones y oponerse a las resoluciones y actos administrativos.

2. Además, los ciudadanos tienen en relación con la utilización de los medios electrónicos en la actividad administrativa, y en los términos previstos en la presente Ley, los siguientes derechos:

a. A elegir, entre aquellos que en cada momento se encuentren disponibles, el canal a través del cual relacionarse por medios electrónicos con las Administraciones Públicas.

b. A no aportar los datos y documentos que obren en poder de las Administraciones Públicas, las cuales utilizaran medios electrónicos para recabar dicha información siempre que, en el caso de datos de carácter personal, se cuente con el consentimiento de los interesados en los términos establecidos por la Ley Orgánica 15/1999, de Protección de Datos de Carácter Personal, o una norma con rango de Ley así lo determine, salvo que existan restricciones conforme a la normativa de aplicación a los datos y documentos recabados. El citado consentimiento podrá emitirse y recabarse por medios electrónicos.

c. A la igualdad en el acceso electrónico a los servicios de las Administraciones Públicas.

d. A conocer por medios electrónicos el estado de tramitación de los procedimientos en los que sean interesados, salvo en los supuestos en que la normativa de aplicación establezca restricciones al acceso a la información sobre aquellos.

e. A obtener copias electrónicas de los documentos electrónicos que formen parte de procedimientos en los que tengan la condición de interesado.

f. A la conservación en formato electrónico por las Administraciones Públicas de los documentos electrónicos que formen parte de un expediente.

g. A obtener los medios de identificación electrónica necesarios, pudiendo las personas físicas utilizar en todo caso los sistemas de firma electrónica del Documento Nacional de Identidad para cualquier trámite electrónico con cualquier Administración Pública.

h. A la utilización de otros sistemas de firma electrónica admitidos en el ámbito de las Administraciones Públicas.

i. A la garantía de la seguridad y confidencialidad de los datos que figuren en los ficheros, sistemas y aplicaciones de las Administraciones Públicas.

j. A la calidad de los servicios públicos prestados por medios electrónicos.

k. A elegir las aplicaciones o sistemas para relacionarse con las Administraciones Públicas siempre y cuando utilicen estándares 
abiertos o, en su caso, aquellos otros que sean de uso generalizado por los ciudadanos.

3. En particular, en los procedimientos relativos al establecimiento de actividades de servicios, los ciudadanos tienen derecho a obtener la siguiente información a través de medios electrónicos:

a. Los procedimientos y trámites necesarios para acceder a las actividades de servicio y para su ejercicio.

b. Los datos de las autoridades competentes en las materias relacionadas con las actividades de servicios, así como de las asociaciones y organizaciones profesionales relacionadas con las mismas.

c. Los medios y condiciones de acceso a los registros y bases de datos públicos relativos a prestadores de actividades de servicios y las vías de recurso en caso de litigio entre cualesquiera autoridades competentes, prestadoras y destinatarios.

En la LAECSP se encuentra tanto derechos de los ciudadanos en su relación general con la Administración por medios electrónicos como derechos que sólo pueden corresponder a quienes estén interesados en un procedimiento que se desarrolle en esta vía. De esta forma, se pueden encontrar dos grupos de estos derechos: por un lado, aquéllos que se individualizan mediante la aplicación al entorno electrónico de los tradicionales del ciudadano en el procedimiento administrativo o en sus relaciones con la Administración, y por otro lado, los derechos que nacen, precisamente de las peculiaridades de esas nuevas relaciones (Blasco, 2007, p. 802).

\subsection{De la figura del Defensor del Usuario de la Administración Electrónica}

Para velar por la efectividad de los derechos reconocidos a los ciudadanos se prevé, en el ámbito de la Administración General del Estado, la actuación de las Inspecciones Generales de Servicios de los Departamentos Ministeriales ${ }^{13}$ y del

13 En lo que se refiere a las Inspecciones Generales de los Servicios de los Departamentos Ministeriales, éstos, son los órganos de la Administración General del Estado que, bajo la superior dirección del ministro correspondiente y la coordinación y dependencia directa del subsecretario, efectúan la tarea permanente de inspección de los servicios, el seguimiento de objetivos y el análisis de riesgos y debilidades de todas las unidades, órganos y organismos vinculados o dependientes de los departamentos ministeriales, atendiendo a los principios de legalidad, eficacia, eficiencia y calidad. En el desarrollo de su actividad, corresponde a las inspecciones generales de servicios de los diferentes ministerios el ejercicio de las siguientes funciones, sin perjuicio de las competencias específicas de otros órganos de su correspondiente ámbito departamental: a) Inspeccionar y supervisar la actuación y el funcionamiento de las unidades, órganos y organismos vinculados o dependientes del departamento, para garantizar el cumplimiento de la normativa vigente; b) Analizar, cuando así les sea encomendado, la estructura de las unidades administrativas del departamento y formular, en su caso, propuestas de reforma y modernización, así como informar sobre las actuaciones que el departamento proyecte realizar en materia de planificación y reorganización de servicios. Asimismo, cuando así les sea encomendado, evaluar el desempeño de los empleados públicos para 
Defensor del usuario, sin perjuicio de las competencias atribuidas en este ámbito a otros órganos o entidades de derecho público.

Tanto las Inspecciones como el Defensor del usuario tendrán una relación muy importante como veremos más adelante. En este capítulo nos centraremos en el estudio de la figura del Defensor del Usuario y de otras formas de garantizar los derechos de los ciudadanos ante la Administración electrónica, no contempladas en la LAECSP pero que resulta interesante su análisis

\subsubsection{Defensor del usuario de la Administración electrónica en España.}

En páginas anteriores habíamos establecido que uno de los aspectos más importantes de la LAECSP era precisamente la creación de la figura del Defensor de los derechos del usuario frente a la Administración electrónica ${ }^{14}$. Es el Art. 7 el que señala que en la Administración General del Estado, se crea la figura del Defensor del usuario de la administración electrónica, que velara por la garantía de los derechos reconocidos a los ciudadanos en la presente Ley, sin perjuicio de las competencias atribuidas en este ámbito a otros órganos o entidades de derecho público.

Inmediatamente en ese mismo precepto señala la manera en que este habrá de ser nombrado y la manera en que estará integrado, y desarrollará sus funciones. En cuanto al nombramiento este será hecho por el Consejo de Ministros a propuesta

optimizar la utilización de los recursos humanos y proponer, en su caso, medidas de reasignación de efectivos; c) Colaborar, en su caso, con la correspondiente Secretaría General Técnica u otros órganos competentes del departamento, en la simplificación, agilización y transparencia de los procedimientos de actuación administrativa; d) Realizar auditorías internas en las unidades y servicios y verificar el desarrollo y cumplimiento de planes y programas de actuación, así como el ajuste de los resultados a los objetivos propuestos; e) Colaborar en la evaluación del rendimiento de las unidades y servicios públicos, analizar riesgos y debilidades y proponer medidas de actuación; f) Participar en el desarrollo de programas de calidad y en su evaluación; g) Verificar y efectuar el seguimiento de las reclamaciones y denuncias de los ciudadanos, así como de las actuaciones y contestaciones de la Administración, en los términos establecidos en el Real Decreto 208/1996, de 9 de febrero, por el que se regulan los servicios de información administrativa y atención al ciudadano; h) Examinar actuaciones presuntamente irregulares de los empleados públicos en el desempeño de sus funciones y proponer, en su caso, a los órganos competentes la adopción de las medidas oportunas; i) Informar las solicitudes de compatibilidad de los empleados públicos de acuerdo con lo que establezcan las normas internas de su departamento; j) Promover actuaciones que favorezcan la integridad profesional y comportamientos éticos de los empleados públicos y de las organizaciones; k) Cualquiera otra función que, dentro de la naturaleza de las competencias propias de las inspecciones generales de servicios, les sea atribuida por el ordenamiento jurídico vigente o les pueda ser asignada por el ministro o el subsecretario del departamento correspondiente. Art. 1 y 2 del Real Decreto 799/2005, de 1 de julio, por el que se regulan las inspecciones generales de servicios de los Departamentos Ministeriales (boe núm. 168, de 15 de julio de 2005)

14 La figura instituida en el art. 7 de la LAECSP estuvo sometida a diversos vaivenes en el proceso legislativo. En el Anteproyecto no figuraba su existencia, sino que la función de velar por el respeto de los derechos citados en dicha Ley se consignaba a las Inspecciones Generales de Servicios de los Departamentos Ministeriales, la Comisión Coordinadora de ésta y la elaboración del informe anual a elevar al Consejo de Ministros se atribuía a la Inspección General de Servicios de la Administración Pública. Finalmente el Defensor aparece nuevamente en el texto del Congreso para su remisión al Senado. 
del Ministro de Administraciones Públicas entre personas de reconocido prestigio en la materia. Estará integrado en el Ministerio de Administraciones Públicas y desarrollará sus funciones con imparcialidad e independencia funcional.

En líneas anteriores hablábamos de la relación entre el defensor del usuario y las Inspecciones Generales de Servicios de los Departamentos Ministeriales, y es que esa relación deriva en cuanto que, para el desarrollo de las funciones a realizar por parte del Defensor, éste deberá contar con el apoyo o asistencia de las Inspecciones.

En particular, el Art. 7 en su apartado 3 las Inspecciones de los Servicios le asistirán en la elaboración del informe y le mantendrán permanentemente informado de las quejas y sugerencias que se reciban en relación con la prestación de servicios públicos a través de medios electrónicos. Asimismo contará con los recursos de la AGE.

El Defensor del usuario de la administración electrónica elaborará, con carácter anual, un informe (el que mencionábamos en el párrafo anterior con la asistencia de las Inspecciones) el cual se elevará al Consejo de Ministros y se remitirá al Congreso de los Diputados. Dicho informe contendrá un análisis de las quejas y sugerencia recibidas, así como la propuesta de las actuaciones y medidas a adoptar en relación a la garantía de los derechos del usuario frente a las Administraciones electrónicas.

Existen dos posiciones respecto a la figura del Defensor del usuario de la Administración electrónica. Por un lado, se ve a esta figura poco sólida por cuanto a su escasa legitimación en su nombramiento por el gobierno; y por las nulas garantías respecto de su nombramiento y cese; y además de estar limitado en medios, al depender de estructuras de Inspección de Servicios previamente existentes (Cotino, 2004).

Por otro lado, una de las barreras con las que se encuentra la Administración electrónica para su desarrollo es con la inseguridad y desconfianza que puede generar en muchos usuarios la utilización de las TIC. Con la LAECSP se intenta atajar dicho obstáculo mediante la creación de la figura del Defensor del Usuario (Mesa del Olmo, 2007).

Además, la figura del Defensor del usuario además de recabar información sobre quejas, reclamaciones y sugerencias del ámbito propio de la AGE y sus organismos, el Defensor habría de instituirse en un observatorio central de implantación de la LAECSP por todas las Administraciones. Sería un canalizador de la información sobre la vigencia efectiva de los derechos de la LAECSP.

Lo cierto es, que la figura del Defensor del usuario de la Administración electrónica solo queda establecida en la Ley, sin existir nombramiento y sin estar llevando a cabo las tareas encomendadas por dicha Ley. En los últimos tiempos han crecido las figuras inspiradas en el Ombudsman que dispersan y parcelan el sistema de garantías haciendo que se pierda visión de conjunto. Quizás fuera más eficaz no dispersar esos esfuerzos y concentrarse más en fortalecer la figura del Defensor del Pueblo y los defensores autonómicos (Fernández, 2007). 
Esto quiere decir que más que crear una figura independiente vendría a ser una figura adjunta que fortalecería las funciones del Defensor del Pueblo que conocerá de los derechos que tienen los ciudadanos cuando realicen un procedimiento por medios electrónicos con la Administración, de esa forma la figura del Defensor del Usuario ya no será esa figura con la que irremediablemente la Institución tendrá una estrecha colaboración y con la que habrá que definir, una vez esté constituida, la mejor forma de cooperación y relación posible para articular la defensa de estos "nuevos derechos ciudadanos" de forma semejante a la estrecha relación que hoy en día mantiene con otra instituciones como, por ejemplo, la Agencia Española de Protección de Datos ${ }^{15}$.

El argumento anterior tiene sentido si observamos que tanto las actividades a realizar por parte de cada una de estas figuras son muy similares. Tanto la actividad a realizar por el Defensor del usuario de la Administración electrónica establecida en el Art. 7.2, así como la establecida en la Ley Orgánica 3/1981, de 6 de abril, del Defensor del Pueblo que en su artículo 33.1 establece que el Defensor del Pueblo en su informe anual dará cuenta del número y tipo de quejas presentadas; de aquellas que hubiesen sido rechazadas y sus causas, así como de las que fueron objeto de investigación y el resultado de la misma, con especificación de las sugerencias o recomendaciones admitidas por las Administraciones públicas.

Un informe conjunto con una parte dedicada a la administración electrónica, además de la utilización de los recursos con los que ya cuenta el Defensor del Pueblo, suponen no sólo un ahorro, sobre todo en tiempos de crisis como los actuales, sino que de forma más ágil se empiezan a llevar a cabo las tareas que se tienen encomendadas.

\subsubsection{Defensor del usuario de la Administración electrónica en las CC.AA.}

De la misma forma que sucede con la AGE, en las comunidades autónomas, se ha puesto en marcha el desarrollo e impulso de la Administración electrónica, aunque hay que hacer notar que este desarrollo ha sido muy diferente para cada uno de ellas y en su relación con la AGE, pero todos siguiendo una misma trayectoria. Esto quiere decir que, cada una de las administraciones autonómicas tienen sus particulares programas de modernización administrativa, con lo cual, en lo que se refiere a las TIC se han ido implementando unidades directivas orientadas a la transformación hacia la Administración electrónica (Galván y García, 2007).

En la LAECSP en su Artículo 2 en el apartado a, señala que esta Ley será de aplicación a: las Administraciones Públicas, entendiendo por tales la Administración General del Estado, las Administraciones de las Comunidades Autónomas y las Entidades que integran la Administración Local, así como las entidades de derecho público vinculadas o dependientes de las mismas.

15 Defensor del Pueblo, sociedad de la información en las Administraciones públicas, 16 de septiembre de 2008. www.defensordelpueblo.es 
En la disposición final tercera, se señalan las fechas para la efectividad plena del derecho de los ciudadanos a relacionarse con las Administraciones Públicas por medios electrónicos, estableciendo los plazos que se consideran adecuados para llevar a cabo las necesarias actuaciones previas de adecuación por parte de las distintas Administraciones Públicas.

En este sentido, la adaptación de Administraciones Públicas para el ejercicio de los derechos reconocidos en el Artículo 6 de la LAECSP, en el ámbito de las Comunidades Autónomas, será posible en relación con la totalidad de los procedimientos y actuaciones de su competencia a partir del 31 de diciembre de 2009 siempre que lo permitan sus disponibilidades presupuestarias.

De esta manera, ninguna de las CC.AA. al igual que la AGE han creado la figura del Defensor del usuario de la Administración electrónica, y siguiendo esa línea, es el mismo Defensor autonómico el que, por lo pronto realiza las funciones encomendadas al Defensor del usurario de la Administración electrónica.

\subsubsection{Defensor del usuario de la Administración electrónica en la Unión Europea.}

Relativamente a la figura del defensor del usuario de la administración electrónica, esta figura jurídica no existe a nivel europeo. Todavía, cada Estado miembro dispone de sus propios procedimientos extrajudiciales para resolver litigios entre los ciudadanos y la administración. Éstos incluyen, por ejemplo, el Defensor del Pueblo nacional, las Comisiones nacionales de peticiones y diversos procedimientos de conciliación. Las funciones y estructuras difieren considerablemente de un Estado miembro a otro.

En este sentido, ante la pregunta de ¿quién se encargaría de velar por los derechos de los usuarios de la Administración electrónica en el ámbito de la Unión Europea? Podemos señalar que de acuerdo a lo ya establecido en los puntos anteriores del caso de la figura del Defensor del Usuario en España, que quien se encargaría de velar por los derechos de los usuarios de la Administración electrónica en la Unión Europea es el Defensor del Pueblo Europeo.

Es necesario dejar claramente establecido que el Defensor del Pueblo Europeo está autorizado a investigar la administración europea y sus relaciones con los ciudadanos y las empresas. Puede recibir reclamaciones referentes a la mala administración ${ }^{16}$ en la acción de la Comisión y de las demás instituciones de la UE, a excepción del Tribunal de Justicia y del Tribunal de Primera Instancia, en el ejercicio de su función jurisdiccional. Algunos de los problemas más comunes que aborda el Defensor del Pueblo Europeo son las irregularidades administrativas injusticia discriminación

16 Hay mala administración cuando una institución no actúa de acuerdo con la ley, no respeta los principios de buena administración, o viola los derechos humanos. 
abuso de poder falta de respuesta denegación de acceso a la información retraso innecesario .

Asimismo, el Defensor del Pueblo Europeo no tiene la facultad de tramitar reclamaciones contra las administraciones nacionales, regionales o locales de los Estados miembros. Estas reclamaciones pueden dirigirse, en el ámbito nacional, al defensor del pueblo correspondiente u organismo similar del Estado miembro de que se trate.

Lo que el Defensor del Pueblo, vendrá a realizar será que, cuando él considere que ha existido un caso de mala administración por parte de una institución de la UE, intentará encontrar una solución aceptable para ambas partes. Si lo estima necesario, formulará recomendaciones a la institución afectada sobre cómo solucionarlo. Si la institución afectada no aplica sus recomendaciones en el plazo de tres meses o no encuentra otra solución satisfactoria para poner fin a la mala administración, el Defensor del Pueblo Europeo enviará un informe especial al Parlamento Europeo.

El Defensor del Pueblo Europeo le mantendrá informado del resultado de sus investigaciones, del dictamen emitido por la institución afectada y de cualquier recomendación que formule.

\subsection{Cartas de servicios electrónicos}

La LAECSP reconoce el derecho de los ciudadanos a relacionarse con las Administraciones Públicas por medios electrónicos, y la correlativa obligación de las Administraciones de facilitarles el acceso a sus servicios a través de dichos medios.

El programa de cartas de servicios, integrado dentro del marco general para la mejora de la calidad en la Administración General del Estado, establece que los organismos que cuenten con servicios electrónicos operativos, públicarán cartas de este tipo de servicios.

El R. D. 951/2005, de 29 de julio, por el que se establece el marco general para la mejora de la calidad en la Administración General del Estado recoge dentro de sus programas, el referido a la públicación de las Cartas de Servicios Electrónicos operativos $^{17}$.

17 Dentro de los organismos y departamentos públicos que cuentan con estas cartas se encuentran Presidencia del Gobierno, Consejo Superior de Deportes; Ministerio de Defensa: Clases Pasivas Militares, Instituto Social de las Fuerzas Armadas, Instituto para la Vivienda de las Fuerzas Armadas, Fondo de Explotación de los .Servicios de Cría Caballar y Remonta, Plan de Pensiones de la Administración del Estado en el Ministerio de Defensa; Ministerio de Economía y Hacienda: Dirección General de Costes de Personal y Pensiones Públicas, Dirección General del Catastro; Ministerio de Medio Ambiente y Medio Rural y Marino: Fondo Español de Garantía Agraria (FEGA); Ministerio de la Presidencia: Ministerio de la Presidencia, Agencia Estatal Boletín Oficial del Estado, Centro de Estudios Políticos y Constitucionales, Consejo de Administración del Patrimonio Nacional, Instituto Nacional de Administración Pública, Mutualidad de Funcionarios Civiles del Estado. Disponible en: http://www.060.es/guia_del_estado/como_trabaja_la_ administracion/calidad/calidad_cartas_servicios_electronicos-ides-idwe-b.html 
Estos documentos pretenden informar a los ciudadanos acerca de los servicios electrónicos que se encuentran a su disposición, indicando las especificaciones técnicas de uso y los compromisos de calidad asumidos en su prestación por los departamentos y organismos públicos, de modo que los usuarios de estos servicios puedan intervenir más activamente en la mejora de la Administración.

\subsection{Cláusulas legales o condiciones de uso}

Respecto de las Cláusulas legales o condiciones de uso estas son unas reglas que rigen la prestación de los servicios públicos electrónicos. Sin embargo, debe ponerse de relieve que en muchos casos las clausulas legales tienen un contenido que supera con creces lo establecido en la ley (Cerrillo, 2008a, p. 65).

En la utilización de las páginas web quedan señalados los términos u condiciones de la misma y deja a elección del usuario el aceptar o no su sometimiento a la misma. Además, algunas de estas cláusulas llegan a señalar cuando ciertos usos de la página web que se está utilizando, están prohibidos y equivale al uso erróneo del sistema o de la misma página web. Al final estas condiciones constituyen un acuerdo legal entre el usuario y la misma página web nosotros que sólo se puede modificar con el consentimiento mutuo. Aunque también es necesario hacer notar el derecho que tienen quienes suministran el servicio a modificar los términos y condiciones de la página web utilizada la cual se hace de manera discrecional. Las condiciones modificadas entran en vigor en el momento en el que el usuario accede a la página web.

\section{CONCLUSIONES}

El desarrollo de la Administración Electrónica en España ha pasado por diferentes fases, desde la presentación informativa de procedimientos a realizar para la tramitación de expedientes a los ciudadanos, hasta la puesta en línea de distintos servicios de algunos Ministerios con un nivel completo de tramitación; desde la presentación de instancias hasta la resolución y notificación por vías telemáticas.

La situación actual de servicios en línea de los distintos Ministerios es muy variada, existen algunos ministerios que disponen de todos sus servicios accesibles electrónicamente y existen otros que cuyos servicios o prestaciones son limitadas. Esta situación en donde no existe una homogeneidad en los servicios en línea y la incipiente creación de servicios comunes, ha llevado a la necesidad de definir un marco legal y técnico para la implementación coordinada de todos los servicios electrónicos de las Administraciones Públicas.

De esta forma, con la recién expedida Ley de acceso electrónico de los ciudadanos a los Servicios Públicos viene a constituir el mecanismo para hacer realidad la Administración Electrónica. Esta Ley impone un conjunto de obligaciones a las 
Administraciones, para hacer efectivos los derechos que se reconocen a los ciudadanos. Además, contempla un plan de actuación para desarrollar una Administración más próxima al ciudadano, más transparente, accesible 24 horas 7 días a la semana, sin colas ni esperas, lo que va a reducir sustancialmente los costes de la Administración y redundar muy positivamente en la economía y calidad de vida de los ciudadanos, así como en la competitividad de las empresas.

Desde la expedición de la LAECSP en el año 2007, quedaba establecido que las pautas a seguir dentro de los tres años siguientes eran por un lado que la Administración General del Estado debe proporcionar el acceso electrónico a la totalidad de sus servicios y para los cuales se recomienda desarrollar procedimientos homogéneos que permitan conocer el uso y las demandas que realizan los ciudadanos sobre estos servicios.

Ahora bien, la Ley de acceso electrónico de los ciudadanos a los Servicios Públicos crea un nuevo marco de relación entre ciudadanos y Administraciones, cambia el esquema de relaciones interdepartamental y fomenta el desarrollo de los servicios departamentales y servicios comunes. Sin embargo, el desarrollo de la Ley debe ir a acorde a los planes que en materia de administración electrónica se desarrollen y con lo cual se garantice la implantación completa de lo establecida en dicha Ley en los plazos previsto en la misma.

La completa aplicación de la LAECSP requiere su pertinente desarrollo reglamentario mediante Real Decreto. Hay puntos claramente necesitados de concreción y desarrollo reglamentado, como el alcance de determinados derechos de los ciudadanos o por el cual se crea la figura del Defensor del usuario de la Administración electrónica.

En la actualidad, la figura del Defensor del usuario de la Administración electrónica, sólo aparece en el texto legal señalando su nombramiento, estructura y funciones a desempeñar. En la misma ley se señala que, por vía reglamentaria se determinará el estatuto del Defensor del Usuario de la Administración Electrónica. Hoy en día sólo existe un anteproyecto de Real Decreto para aprobar el estatuto del Defensor del usuario de la Administración electrónica. Esto quiere decir que actualmente no existe esta institución y por lo tanto nadie se encarga de dichas funciones. Se pretende que entre tanto, la figura del defensor del Pueblo sea quien reciba las quejas que en esta materia puedan darse, pero a tal efecto no existe ningún documento legal que así lo señale.

El desarrollo de la Ley de acceso electrónico quedará por tanto dependiendo del desarrollo de la Administración electrónica, es decir, del desarrollo de los planes o políticas en esta materia, que estén dirigidos a la implementación de servicios e infraestructuras comunes, la creación del marco pleno de servicios en línea, el fomento de la igualdad de derechos del ciudadano y el libre acceso a los servicios por ciudadanos y empresas. 


\section{ABREVIATURAS}

\begin{tabular}{|c|c|}
\hline AGE & Administración General del Estado \\
\hline Art. & Artículo \\
\hline $\mathrm{BOE}$ & Boletín Oficial del Estado \\
\hline CC.AA. & Comunidades Autónomas \\
\hline $\mathrm{CE}$ & Constitución Española de 1978 \\
\hline DNI & Documento Nacional de Identidad \\
\hline LAECSP & $\begin{array}{l}\text { Ley } 11 / 2007 \text { de } 22 \text { de junio, de de acceso electrónico de los } \\
\text { ciudadanos a los Servicios Públicos. }\end{array}$ \\
\hline \multirow[t]{3}{*}{ LRJAP y PAC Ley } & 30/1992, de 26 de noviembre, de Régimen Jurídico de las \\
\hline & Administraciones Públicas y del Procedimiento \\
\hline & Administrativo Común. \\
\hline NGP & Nueva Gestión Pública \\
\hline R.D. & Real Decreto \\
\hline TIC & Tecnologías de la Información y Comunicaciones \\
\hline UE & Unión Europea \\
\hline
\end{tabular}

\section{REFERENCIAS}

Agirreazkuenaga, I., y Chinchilla, C. (2001). El uso de medios electrónicos en el ámbito de las Administraciones Públicas. Revista Española de Derecho Administrativo (109), enero-marzo, 36-59.

Álvarez-Cienfuegos, J. M. (2001). La nueva administración electrónica y las notificaciones efectuadas por medios telemáticos. Revista Jurídica de Navarra (32), 77-94.

Barriuso, C. (2007). Administración Electrónica, 1a . ed., Madrid: editorial Dykinson.

BERMEJO, F. (2003). Democracia electrónica, participación ciudadana y juventud, Estudios de Juventud (61).

Blasco, J. L. (2007). Los derechos de los ciudadanos en su relación electrónica con la Administración. Revista Española de Derecho Administrativo (136), 791-821.

Carta Iberoamericana de gobierno electrónico. (2007). Firmada en la IX Conferencia Iberoamericana de Ministros de Administración Pública de la Reforma del Estado y los Jefes de Delegación de los Gobiernos iberoamericanos, reunidos los días 31 de mayo y $1^{\circ}$ de junio en Pucón, Chile.

Casillas, Mesa y Ramilo, (2005). El desarrollo del gobierno electrónico en los municipios del País Vasco. Cuaderno de la sección de medios de comunicación de Euskolkaskuntza, Mediatika (11). Eusko Ikaskuntza-Sociedad de Estudios Vasco.

Castells, M. (2001). La era de la información 1 la sociedad red. Madrid: Editorial alianza. 
Cerrillo, A. (2008 a). E-administración, 1ª.ed, Barcelona: Editorial UOC. . (2008). Informe sobre la administración local, 1ª ed. Barcelona: Editorial Fundació Carles Pi i Sunyer.

Comunicación de las Comunidades Europeas, COM. (2003). 567 final, de 26.9.2003. Congreso de los Diputados, VIII legislatura. (2007). Boletín Oficial de Las Cortes Generales. Proyectos de Ley 20 de junio de 2007 núm. 116-12 aprobación definitiva por el congreso 121/000116. De acceso electrónico de los ciudadanos a los Servicios Públicos (anteriormente denominado Proyecto de Ley para el acceso electrónico de los ciudadanos a las Administraciones Públicas).

Consejo de Ministros. (2005). Plan Moderniza, de medidas 2006-2008. Disponible en: http://www.map.es/iniciativas/mejora_de_la_administracion_general_del_ estado/moderniza/parrafo/00/document_es/Plan_Moderniza.pdf

Consejo y la Comisión Europea para el Consejo Europeo de Feira. (2000). eEurope 2002: Una Sociedad de la Información para todos. Bruselas: junio 14. Disponible en: http://www.csi.map.es/csi/pdf/actionplan_es.pdf

Comisión al Consejo, al Parlamento Europeo, al Comité Económico y Social y al Comité de las Regiones. (2002). eEurope 2005: una Sociedad de la Información para todos. Plan de acción Comunicación, Bruselas: mayo 28, 263 final. Disponible en: http://www.csi.map.es/csi/pdf/eeurope2005_es.pdf

Cotino, L. (2004). Derechos del ciudadano administrado e igualdad ante la implantación de la administración. Revista Vasca de Administración Pública (68), $125-154$.

. (2007). Retos jurídicos y carencias normativas de la democracia y la participación electrónicas. Revista catalana de dretpúblic (35), 75-120.

Fernandez, J. (2007). Acceso a los ciudadanos a las administraciones públicas y brecha digital, Revista de la Escuela Gallega de Administración Pública: Administración y ciudadanía, 2 (3), 63-80.

Galván, J., y García, P. (2007). La Administración electrónica en España. 1ª ed. Madrid: Ariel, Fundación Telefónica, INAP.

i2010 - Una Sociedad de la Información europea para el crecimiento y el empleo. Comunicación de la Comisión al Consejo, al Parlamento Europeo y al Comité Económico y Social Europeo y al Comité de las Regiones. Bruselas 1.6. 2005, COM (2005) 229. Disponible en: http://europa.eu.int/information_society/ eeurope/i2010/docs/communications/com_229_i2010_310505_fv_es.doc

Iniciativa i2010 - Primer Informe Anual sobre la Sociedad de la Información Europea. (2006). Comunicación de la Comisión al Consejo, al Parlamento Europeo y al Comité Económico y Social Europeo y al Comité de las Regiones. Bruselas 19.5.2006, COM 215. Disponible en: http://europa.eu.int/information_society/ eeurope/i2010/docs/annual_report/com_2006_215_es.pdf

http://www.ingenio2010.es/contenido.asp?dir=./01 
http://www.060.es/guia_del_estado/como_trabaja_la_administracion/calidad/ calidad_cartas_servicios_electronicos-ides-idweb.html

Martín, M. I. (2003). Administración pública y nuevas tecnologías: hacia la administración. Revista Iberoamericana de Administración Pública (10), 155-171.

Martinez, J. Á. (2007). La gestión del conocimiento en la administración electrónica. Madrid: editorial Arco/libro.

Mesa del olmo, A. (2007a). La administración electrónica en el ámbito local del País Vasco: el desarrollo de las páginas web municipales. Revista Vasca de Administración Pública (77), 133-176.

Mesa del Olmo, A. (2007b). Reflexiones en torno a la Administración Electrónica en España y la Aplicación de la Ley de Acceso Electrónico, en Revista Administración y Ciudadanía, 2 (3), 169

Ponjuán, G. (1998).Gestión de información en las organizaciones: principios, conceptos y aplicaciones. Santiago de Chile: CECAPI, Universidad de Chile.

Sancho, D. (2005). El desarrollo de la Administración electrónica en España, ponencia presentada dentro del grupo 7: Sociedad de la Información y Administración Pública. Madrid: el VII Congreso de la AECPA Democracia y Buen Gobierno, 21-23 de septiembre.

Servicios Públicos Digitales Plan Avanza. Disponible en: http://www.planavanza.es/ AreasActuacion/ServiciosPúblicos/Objetivos/Objetivos.htm.

Valero Torrijos, J. (2004). El régimen jurídico de la e-Administración. El uso de medios informáticos y telemáticos en el procedimiento administrativo. Granada: Editorial Comares. 
